\title{
CONSTRUÇÃO DA INFORMAÇÃO QUALITATIVA: UMA TAREFA COMPLEXA
}

DEMO, P. Pesquisa e informação qualitativa: aportes metodológicos. Campinas, SP: Papirus, 2001. (Coleção Papirus Educação).

\section{Rebeca Chiacchio Azevedo Fernandes}

“Pesquisa e informação qualitativa: Aportes metodológicos”, do autor Pedro Demo, é uma interessante leitura para aquele que quer conhecer e entender sobre a pesquisa qualitativa, onde o autor de uma maneira didática e pertinente apresenta uma proposta de “construção da informação qualitativa”.

Partindo do ponto de vista de que entre quantidade e qualidade não existe dicotomia, Demo encara, neste livro, o grande desafio de emprestar credibilidade científica à pesquisa qualitativa. Para isso, recupera a "hermenêutica da profundidade" de Thompson e nessa dialética aberta, alarga a proposta para o estudo de fenômenos intensos, em torno de três pontos básicos: contexto histórico, análise estrutural e análise dialética.

Primeiramente é necessário evidenciar que a pesquisa qualitativa impõe-se sempre que se trate de temas que se interessam mais pela intensidade do que pela extensão dos fenômenos. No entanto, o autor não deixa de reconhecer também que métodos quantitativos e qualitativos precisam ser tomados como complementares, já que qualidade e quantidade são faces diferenciadas do mesmo fenômeno, mas também deixa claro que "O método de captação não pode ser mais importante do que a realidade a ser captada" (DEMO, 2001, p.105).

O autor apóia-se na idéia de argumentação bem fundamentada, sempre discutível, mas respeitável pelo fato de aceitar, a todo o momento, ser questionada e questionar, sendo, para ele, a pesquisa, um diálogo inteligente e crítico com a realidade.

(C) ETD - Educação Temática Digital, Campinas, v.10, n.1, p.240-247, dez. 2008 - ISSN: 1676-2592. 
No Capítulo 1, Acertos categoriais, o autor propõe direcionar o conceito de qualidade para a idéia de “intensidade”, em contraposição dialética com a idéia de “extensão”. Discute então a questão da qualidade (intensidade) e da quantidade (extensão) como sendo faces diferenciadas do mesmo fenômeno, onde a noção de intensidade volta-se para as dimensões do fenômeno marcadas pela profundidade, envolvimento e participação, sendo que, fenômenos que se distinguem pela intensidade indicam que não se esgotam na extensão. "São coisas extensas que produzem a intensidade, bem como todo fenômeno intenso é feito também de coisas extensas“(DEMO, 2001, p.16).

Demo propõe, então, formalizar/sistematizar os dados obtidos por meio da pesquisa qualitativa, porém justifica que esta, apesar de formalizar, procura preservar a realidade acima do método. O autor chama atenção para características da intensidade como profundidade, envolvimento, participação, processualidade, perfectibilidade e politicidade, já que trata da dimensão complementar natural dos fenômenos, que são complexos, e ao contrário do que é extenso, o intenso é profundo.

Nas teorias clássicas ou positivistas, como a sociologia compreensiva de Weber, a noção de sujeito é reservada ao cientista, e o objeto à realidade, a ser investigada. A partir desse apontamento, Demo ilustra no Capítulo 2, Sujeito e Objeto, que a pesquisa, no paradigma de modernidade, foi marcada ostensivamente pela objetividade da realidade e também pela neutralidade do sujeito, correspondendo às expectativas dos métodos de análises.

No pós-modernismo, o paradigma se deslocou para o valor da crença, ou seja, a realidade passou a ser vista não como ela é, mas como podemos percebê-la. Nesse sentido, Demo aponta que, num primeiro momento, o sujeito é atraído pela aparência e não pelo conteúdo presente em determinada realidade. Num segundo momento, com uma análise mais detida são observados os níveis mais profundos e descoberta as minúcias do objeto de pesquisa. 
A realidade que temos em mente é aquela reconstruída por nós. O mundo externo também tem sua influência, ainda que predominem as características do observador. A visão Positivista também reconheceu que neutralidade é tomada de posição, porque não existe posição nenhuma, o ser humano é sujeito e está inserido num contexto temporal e espacial.

Nesse ínterim a objetividade (uma representação fiel de um objeto) é substituída por objetivação (ato de tratar como um objeto), pois, a ciência, não podendo ser objetiva, deve buscar captar a realidade assim como ela é, o que é uma meta essencial para a compreendermos e impossível, pois somos parte dela. A realidade é reconstruída de acordo com nossa história evolucionária, dessa forma, não se apresenta de maneira linear. “Não podemos ver a realidade estritamente de fora porque somos parte dela. Não é viável sair da própria pele para nos vermos de fora” (DEMO, 2001, p.26).

Há diferenças entre ciências naturais e humanas, porém sendo a realidade complexa, não-linear e dinâmica, não cabe em nenhuma disciplina, sendo assim a interdisciplinaridade é exigência da sua própria complexidade e da mente analítica. A realidade é uma para todos, mas pode ser vista de várias maneiras, a diversidade de olhares é essencial para captar realidades tão diversificadas. Métodos e procedimentos podem ser diferentes, variando as respostas, mas a pergunta é a mesma. Quando analisamos dada realidade, também nos analisamos. Na sociedade não há lugar para objetos puros e simples. Trata-se sempre de sujeitos-objetos.

Há uma polêmica quanto a Inteligência Artificial - muitos defendem o representacionismo porque acreditam que o computador represente a realidade em correspondência direta com o cérebro. No entanto, o cérebro vai além de armazenar dados, pois ele é capaz de analisar e interpretar e com o avanço da biologia, autores negam ser o cérebro um computador.

A memória do computador é limitada fisicamente em relação à memória humana, pois o cérebro é resultado de milhões de anos de processo evolutivo - computador é máquina de engenharia capaz de armazenar em sua memória, dados, de forma linear. A 
memória humana é incapaz de apenas guardar informações, pois interage com os dados (lembranças) de maneira dinâmica, por exemplo, se gravarmos em vinte disquetes uma mesma informação eles reproduzirão o mesmo conteúdo, diferente acontece se contarmos a mesma história para vinte pessoas ao chegar à vigésima, tal história se transformará em outra, devido ao envolvimento emocional do ser humano.

A informação qualitativa trabalha com sujeito-objeto e não com mero objeto de análise, como conseqüência, a comunicação se faz pelo que há de implícito do que é explícito. Assim é possível entender o que o autor diz, mas nunca sabemos bem o que de fato ele queria dizer e ele também não sabe exatamente o que queria dizer. Contudo, a informação é resultado da comunicação discutida, permeável à argumentação e interpretada, o sujeito pode questionar o que se diz, e o sujeito-objeto também, buscando uma captação flexível da realidade.

Sabendo disso é necessário adequar metodologia e instrumentos à pesquisa. O exemplo dado por Demo é que numa pesquisa sobre felicidade a coleta de dados se dá por meio de um questionário fechado (pergunta seca - resposta seca). Esse tipo de pesquisa não permite a resposta de uma pergunta complexa com um esquema simples. O contrário acontece quando se propõe uma entrevista aberta (sobre o que é felicidade). É preciso estar atento à interpretação que a mente realiza considerando a interferência natural como um processo “objetivo”.

O contexto apresentado por Pedro Demo aponta que a investigação é realizada a partir da leitura do que está implícito e desse modo a comunicação humana é feita de sutilezas, cabendo ao pesquisador analisar a informação qualitativa levando sempre em conta a condição humana de sujeito-objeto, observando tudo, porque tudo pode estar imbuído de sentido e expressar mais do que a própria fala. “É impossível reduzir o entrevistado a objeto” (DEMO, 2001, p.34). 
Identificada a necessidade de se trabalhar com a pesquisa qualitativa e estando diante da hipótese de trabalho, o referencial teórico deve fazer parte da metodologia qualitativa como questão implícita, inevitável e necessária.

No Capítulo 3, Hermenêutica de Profundidade, À La Thompson, Demo expõe a proposta de análise qualitativa de Thompson, definida por este de "Hermenêutica da profundidade”. Esta proposta está ligada a Análise da Ideologia que possui uma “concepção crítica”, onde ideologia é um discurso, portanto não podemos analisá-la somente pelos seus sentidos aparentes, mas, sobretudo, pelos implícitos.

Sendo assim, este referencial coloca em evidência que o objeto de análise é uma construção simbólica que exige uma interpretação. O mundo sócio-histórico não é apenas um campo-objeto, ele é também um campo-sujeito, um “campo-sujeito-objeto”.

Para Thompson a “interpretação da doxa” é uma interpretação das opiniões, crenças e compreensões que são sustentadas e partilhadas pelas pessoas que constituem o mundo social. No entanto Demo afirma que se compreende melhor a fala de alguém se, além de sabermos o mundo de opiniões e crenças que a cerca, também buscarmos entender sua história de vida, seus projeto sociais coletivos e individuais, o entorno das tradições culturais que demarcam os sentidos, modos de relacionamento com os outros e constituição do grupo de relações mais próximas, e assim por diante. (DEMO, 2001, p.38).

Para ir além da “interpretação da doxa”, devemos passar por três patamares de análise:

1) Contextualização sócio-histórica: alocar no espaço e no tempo o fenômeno pesquisado. Reconstruir as condições sociais e históricas de produção, circulação e recepção das formas simbólicas. As formas simbólicas não podem ser analisadas separadamente dos contextos em que são produzidas e interpretadas.

2) Análise formal: deslindar a estrutura da complexidade dos objetos e expressões que circulam nos campos sociais. Levantar no fluxo da fala o que é recorrente, 
repetitivo, regular, indicando algo estrutural, observando freqüências; códigos; estruturas profundas e argumentação.

3) Interpretação/reinterpretação: Movimento novo do pensamento, síntese, construção criativa de possíveis significados.

a) standpoint epistemology: postura de entendimento do outro assim como o outro gostaria de ser entendido, tentar partir do ponto de vista alheio, da outra cultura, do outro contexto, do outro horizonte de referência.

b) questionamento próprio: assumindo a posição de intérprete autônomo, interpretar o fenômeno pesquisado em tom desconstrutivo, para ir além do que se diz e das aparências do que se diz.

c) Reinterpretação: A circularidade do discurso é intrínseca, por conta da reinterpretação que interpreta o que já está pré-interpretado, mas traz profunda novidade se souber constituir-se como reconstrução crítica.

Tendo como pano de fundo os três passos da análise qualitativa: contextualização sócio-histórica, análise formal e interpretação, o autor, no Capítulo 4, Avaliações Qualitativas, faz uma retomada da idéias anteriores, contextualizando estas questões a partir da avaliação do desempenho qualitativo de associações, que considera um fenômeno central da cidadania organizada popular e decisivo para a qualidade do controle democrático.

A partir da hipótese de trabalho de que o centro da cidadania é o fenômeno emancipatório ou o combate à pobreza política, o autor cerca analiticamente esta dimensão, passando pelas etapas anteriores: contextualização sócio-histórica da associação destaca alguns indicadores de sua estruturação formal, fazem a interpretação segundo a contextualização sócio-histórica e a avaliação formal. 
O autor observa que avaliação qualitativa tem sido insistentemente requisitada na esfera do desempenho educacional e conclui que a qualidade formal e política precisam completar-se, a primeira como instrumento, a segunda como objetiva e ética.

No Capítulo 5, Exercícios Simulados de Dinâmicas Qualitativas, o autor apresenta alguns exercícios simulados de análise hermenêutica, com o intuito de trabalhar a pesquisa e a informação qualitativa no contexto de fenômenos dinâmicos voltados especialmente para depoimentos e ambientes comunicativos.

Através desta visão crítica da análise hermenêutica, o autor analisa as situações tratadas no capítulo e afirma que argumentar é tratar o outro como alguém capaz de ser convencido e capaz de me convencer, o que Thompson chama de "princípio de nãoimposição” que permite o outro “princípio de auto-reflexão”, o que estimula a reflexão entre e por estes sujeitos.

O método de captação não pode ser mais importante do que a realidade a ser captada, afirma Demo no Capítulo 6, Desafios Metodológicos: “Ao mesmo tempo em que busco afastar o risco de receita e aceito o risco da simplificação, o que me interessa é armar uma discussão simultaneamente bem argumentada e útil” (DEMO, 2001, p. 105).

A pesquisa qualitativa acusa o cansaço da pesquisa positivista, não só porque esta tripudiou sobre a ditadura do método, como, sobretudo porque inspira simplificações grosseiras de uma realidade intensamente complexa.

Para o autor entre os principais desafios metodológicos da pesquisa qualitativa está o problema da generalização. Toda pesquisa precisa saber mesclar quantidade e qualidade, forma e intensidade, estrutura e dinâmica. A pesquisa qualitativa apenas quer realçar as dinâmicas, mas sem perder de vista que toda dinâmica também revela formas.

O aprofundamento da informação qualitativa ganha muito se for cercado por vários procedimentos convergentes: observação participante, conversa em grupos, levantamentos sócio-históricos, etc. Tais procedimentos favorecem a confiabilidade da informação, porque aparece o cuidado extremo com a coleta e o tratamento dos dados. 
Para concluir, o autor afirma que a pesquisa qualitativa é muito mais difícil, problemática e arriscada que a pesquisa quantitativa e que ao mesmo tempo em que defende a pesquisa qualitativa, crê ter feito esforço honesto para lhe dar credibilidade científica.

Esforço válido, tarefa complexa cumprida! Com a leitura deste livro o leitor compreende como se dá a construção da informação qualitativa, contribuindo para sua compreensão das características, especificidades e procedimentos, podendo utilizá-la quando estiver diante de temas que se interessam mais pela intensidade do que pela extensão dos fenômenos. Porém o leitor não pode perder de vista que métodos quantitativos e qualitativos precisam ser tomados como complementares, já que qualidade e quantidade são faces diferenciadas do mesmo fenômeno e que o mais importante, no entanto, é a realidade a ser captada do que o método de captação.

REBECA CHIACCHIO AZEVEDO FERNANDES

Graduação em Pedagogia. Universidade Estadual de Campinas, UNICAMP, estudante do mestrado em educação, bolsista da FAPESP.

E-mail: rebeca chiacchio@hotmail.com

Recebido em: 28/07/2008

Publicado em: 31/01/2009 